Lukyanchenko Oleksandr I., Mel'nyk Oksana I., Gozhenko Olena A., Zukow Walery, Popovych Igor L. Features of the HRV, endocrine and metabolic parameters in persons whose immune status is susceptible or resistant to chronic stress. Journal of Education, Health and Sport. 2020;10(3):177-187. eISSN 2391-8306. DOI http://dx.doi.org/10.12775/JEHS.2020.10.03.020 https://apcz.umk.pl/czasopisma/index.php/JEHS/article/view/JEHS.2020.10.03.020 https://zenodo.org/record/3753225

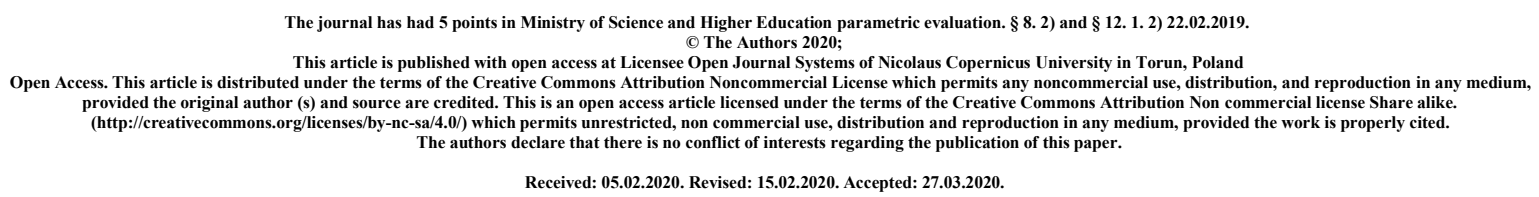

\title{
FEATURES OF THE HRV, ENDOCRINE AND METABOLIC PARAMETERS IN PERSONS WHOSE IMMUNE STATUS IS SUSCEPTIBLE OR RESISTANT TO CHRONIC STRESS
}

\author{
Oleksandr I. Lukyanchenko', Oksana I. Mel'nyk², Olena A. Gozhenko', \\ Walery Zukow ${ }^{3}$, Igor L. Popovych ${ }^{1,4}$ \\ ${ }^{1}$ Ukrainian Scientific Research Institute of Medicine for Transport, Odesa, Ukraine \\ sofia.lukyanchenko@gmail.com; eago@ukr.net \\ ${ }^{2}$ Danylo Halyts'kyǐ National Medical University, L'viv, Ukraine omelnyk7@gmail.com \\ ${ }^{3}$ Nicolaus Copernicus University, Torun, Poland w.zukow@wp.pl \\ ${ }^{4}$ OO Bohomolets' Institute of Physiology, Kyïv, Ukraine i.popovych@biph.kiev.ua
}

\begin{abstract}
Background. In the previous studies, we compared the individuals who were almost identical to the average value of LF/HF ratio and its dispersion, but with opposite deviations from the norm of immunity. Two profiles of EEG have been created that reflect the differences between the two clusters. The first profile contains the parameters that in stress-sensitive individuals are in the zone of narrowed norm, whereas in stress-resistant individuals they are to some degree elevated, or at least exceed those in stress-sensitive individuals. The second profile contains EEG parameters, each of which in stress-resistant individuals is lower than that of stresssensitive individuals. The purpose of this study is to clarify the features of the HRV, endocrine and metabolic parameters in persons whose immune status is susceptible or resistant to chronic stress. Materials and Methods. The object of observation were 32 men and 8 women with chronic pyelonephritis in remission. The criterion for inclusion was the magnitude of the sympathico-vagal balance index LF/HF which exceeded the age norm by 0,5 $\sigma$. We determined spectral parameters of HRV, plasma levels of principal adaptation Hormones, plasma and daily urine levels of the Electrolytes and Nitrous metabolites as well as plasma Lipoproteines spectrum. Results. Discriminant analysis revealed that Testosterone is the main factor that conditioning the sensitivity of immune status to sympathotonic shift in autonomic regulation in chronic stress. Sensitizing (immunosuppressive) factors are also $\mathrm{Ca} / \mathrm{K}$-ratio of plasma and total Cholesterol, instead LD LP Cholesterol, Creatininuria, P/Ca-ratio of urine, spectral power of VLF band HRV as well as entropy of HRV are desensitizing (immunoprotective) factors. Conclusion. The susceptibility or resistance of the immune status to the stress sympathotonic shift of autonomic regulation is conditioned by the combination of EEG, HRV, endocrine and metabolic parameters.
\end{abstract}

Key words: Chronic Stress; Immunity; HRV; Hormones; Metabolism. 


\section{INTRODUCTION}

To elucidate the role of chronic stress-induced changes in sympatho-vagal balance in changes in immunity, previosly we compared the individuals who were retrospectively divided into two groups, almost identical to the average value of LF/HF ratio and its dispersion, but with opposite deviations from the norm of the links of immunity. In stresssensitive individuals versus stress-resistant individuals integral state of Phagocytosis as Zscores was compiled: $-1,82 \pm 0,39$ and $+0,76 \pm 0,43$; of Cellular link: $-1,69 \pm 0,21$ and $+0,23 \pm 0,26$, of Humoral link: $+0,23 \pm 0,19$ and $+0,76 \pm 0,11$ respectively [15].

In next study [16], after the EEG parameters screening, two profiles have been created that reflect the differences between the two clusters of individuals. The first profile contains the parameters that in stress-sensitive individuals are in the zone of narrowed norm, whereas in stress-resistant individuals they are to some degree elevated, or at least exceed those in stress-sensitive individuals. The second profile contains EEG parameters, each of which in stress-resistant individuals is lower than that of stress-sensitive individuals.

The purpose of this study is to clarify the features of the HRV, endocrine and metabolic parameters in persons whose immune status is susceptible or resistant to chronic stress.

\section{MATERIALS AND METHODS}

The object of observation were 32 men (aged 24-70 years old) and 8 women (39-71 years old) with chronic pyelonephritis in remission. The criterion for inclusion was the magnitude of the sympathico-vagal balance index LF/HF, which exceeded the age norm by $0,5 \sigma$.

For this purpose, we recorded electrocardiogram in II lead to assess the parameters of HRV (software and hardware complex "CardioLab+HRV" production "KhAI-MEDICA", Kharkiv, Ukraine). For further analysis the following spectral parameters (Frequency Domain Methods) were selected. Spectral power (SP) bands: high-frequency (HF, range $0,4 \div 0,15 \mathrm{~Hz}$ ), low-frequency ( $\mathrm{LF}$, range $0,15 \div 0,04 \mathrm{~Hz}$ ), very low-frequency (VLF, range $0,04 \div 0,015 \mathrm{~Hz}$ ) and ultra low-frequency (ULF, range $0,015 \div 0,003 \mathrm{~Hz}$ ) $[1,3,7]$. We calculated also the Entropy (h) of normalized SP using CE Shannon's formula [17]:

$\mathrm{hHRV}=-\left[\mathrm{SPDHF} \bullet \log _{2} \mathrm{SPDHF}+\mathrm{SPDLF} \cdot \log _{2} \mathrm{SPDLF}+\mathrm{SPDVLF} \bullet \log _{2} \mathrm{SPDVLF}+\mathrm{SPDULF} \bullet \log _{2} \mathrm{SPDULF}\right] / \log _{2} 4$.

To assess endocrine status in the morning on an empty stomach we determined plasma levels of principal adaptation Hormones: Cortisol, Testosterone and Triiodothyronine (by the ELISA with the use of analyzer "RT-2100C" and corresponding sets of reagents from "Алкор Био", XЕMA Co, Ltd and DRG International Inc).

According Instruction for the determination of Testosterone in human serum or plasma, the following normal range $(\mathrm{nM} / \mathrm{L})$ is recommended: femals $0,15 \div 4,6$; males $20-39$ yrs $9,0 \div 38 ; 40-55$ yrs $6,9 \div 21 ;>55$ yrs $5,9 \div 18,1$. Resting on this repering points, YL Hrytsak et al

[9] builded regressive model for calculation of normal averages for males from 20 to 69 years (Fig. 1). 


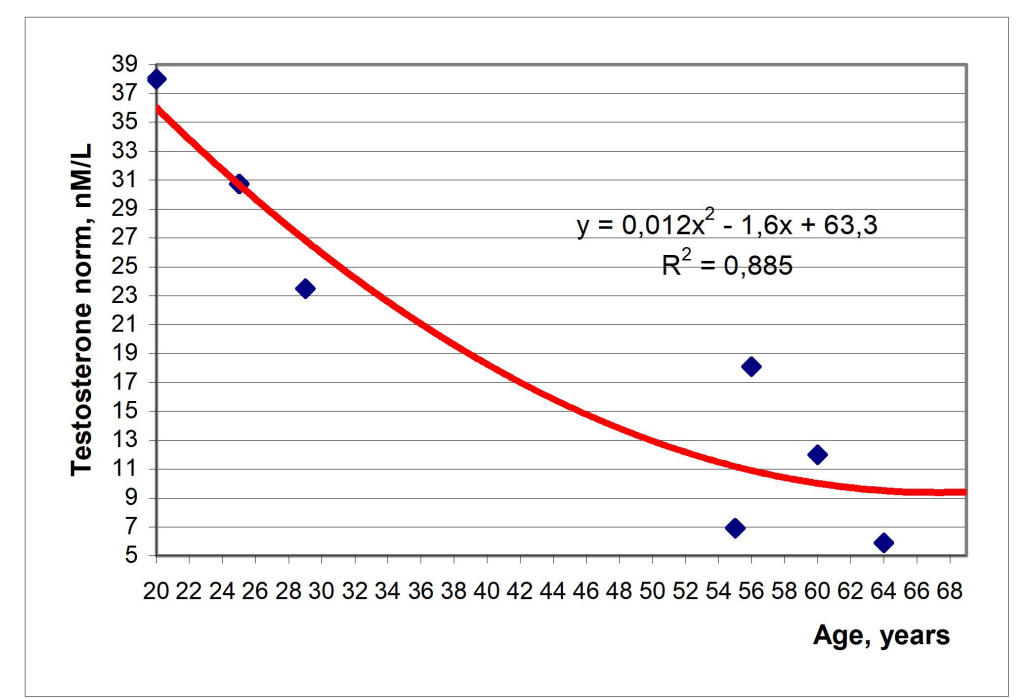

Fig. 1. Testosterone normal averages for males various age

Then we determined the plasma and daily urine levels of the Electrolytes: calcium (by reaction with arsenase III), magnesium (by reaction with colgamite), phosphates (phosphatemolybdate method), chloride (mercury-rhodanidine method), sodium and potassium (flamming photometry); Nitrous metabolites: creatinine (by Jaffe's color reaction by Popper's method), urea (urease method by reaction with phenolhypochlorite), uric acid (uricase method).

According to the parameters of electrolyte exchange, hormonal activity was evaluated: parathyroid by coefficients $(\mathrm{Cap} / \mathrm{Pp})^{0,5}$ and $(\mathrm{Pu} / \mathrm{Cau})^{0,5}$, calcitonin by coefficients $(\mathrm{Cap} \bullet \mathrm{Pp})^{-0,5}$ and $(\mathrm{Cau} \cdot \mathrm{Pu})^{0,5}$ as well as mineralocorticoid by coefficients $(\mathrm{Nap} / \mathrm{Kp})^{0,5}$ and $(\mathrm{Ku} / \mathrm{Nau})^{0,5}$, based on their classical effects and recommendations by IL Popovych [6].

We estimated also plasma Lipoproteines spectrum: total cholesterol (by a direct method after the classic reaction by Zlatkis-Zack) and content of him in composition of $\alpha$-lipoproteins (by the enzyme method by G Hiller [8] after precipitation of not $\alpha$-lipoproteins); prae- $\beta$ lipoproteins (expected by the level of triacylglycerides, by a certain meta-periodate method); $\beta$-lipoproteins (expected by a difference between a total cholesterol and cholesterol in composition $\alpha$-and prae- $\beta$-lipoproteins).

It is known that levels of uric acid and lipoprotein cholesterol are significantly dependent on gender and age. Using reference data $[10,11]$, we created a gender and age standard for each patient (Figs. 2-5). 


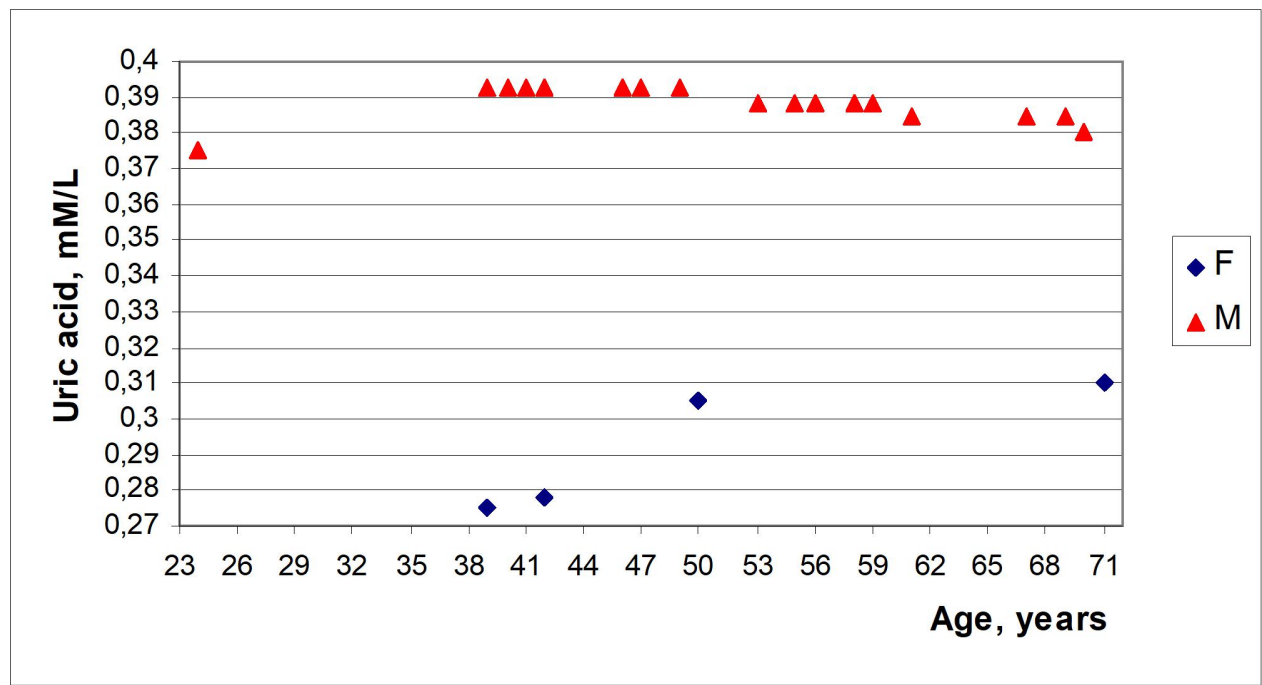

Fig. 2. Age and sex standards of uricemia

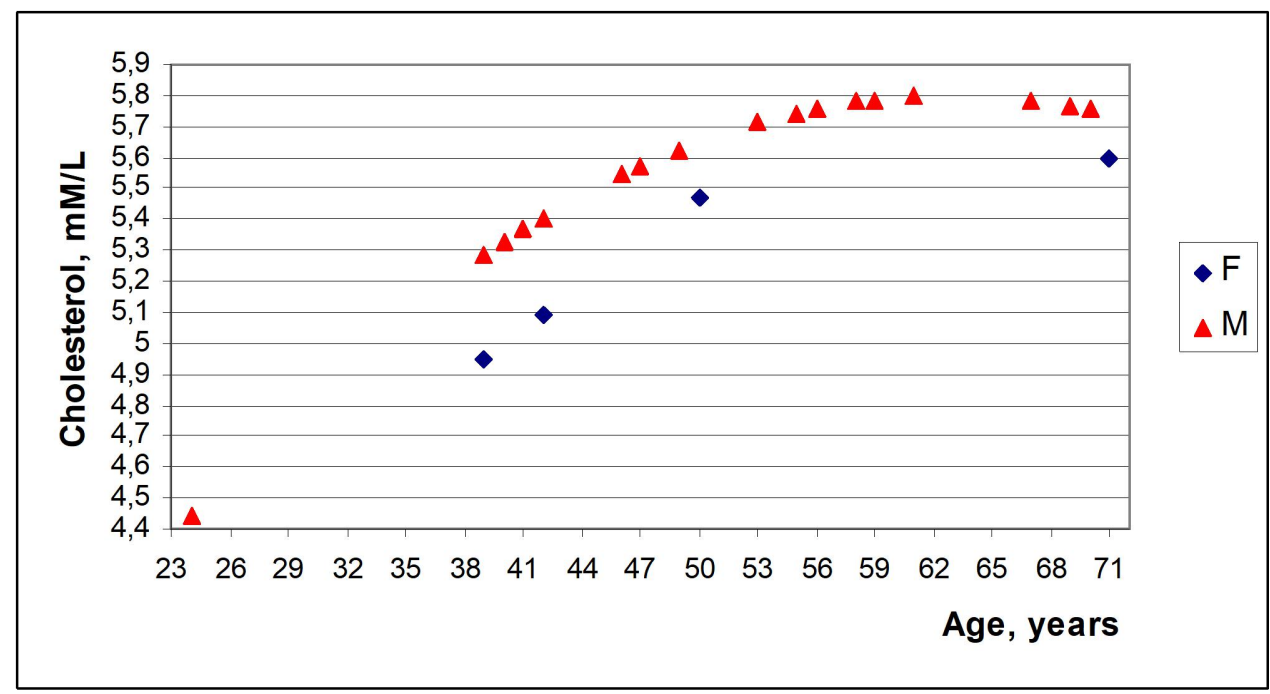

Fig. 3. Age and sex standards of plasma total cholesterol

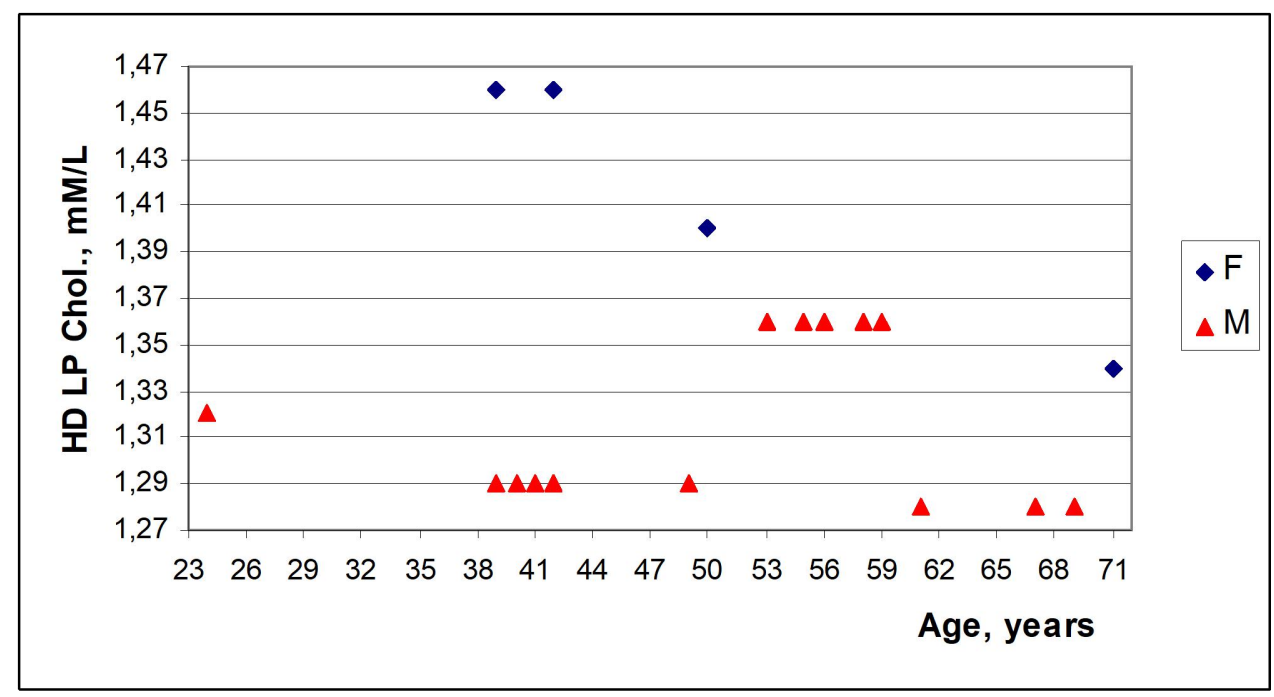

Fig. 4. Age and sex standards of hight-density lipoprotein plasma cholesterol 


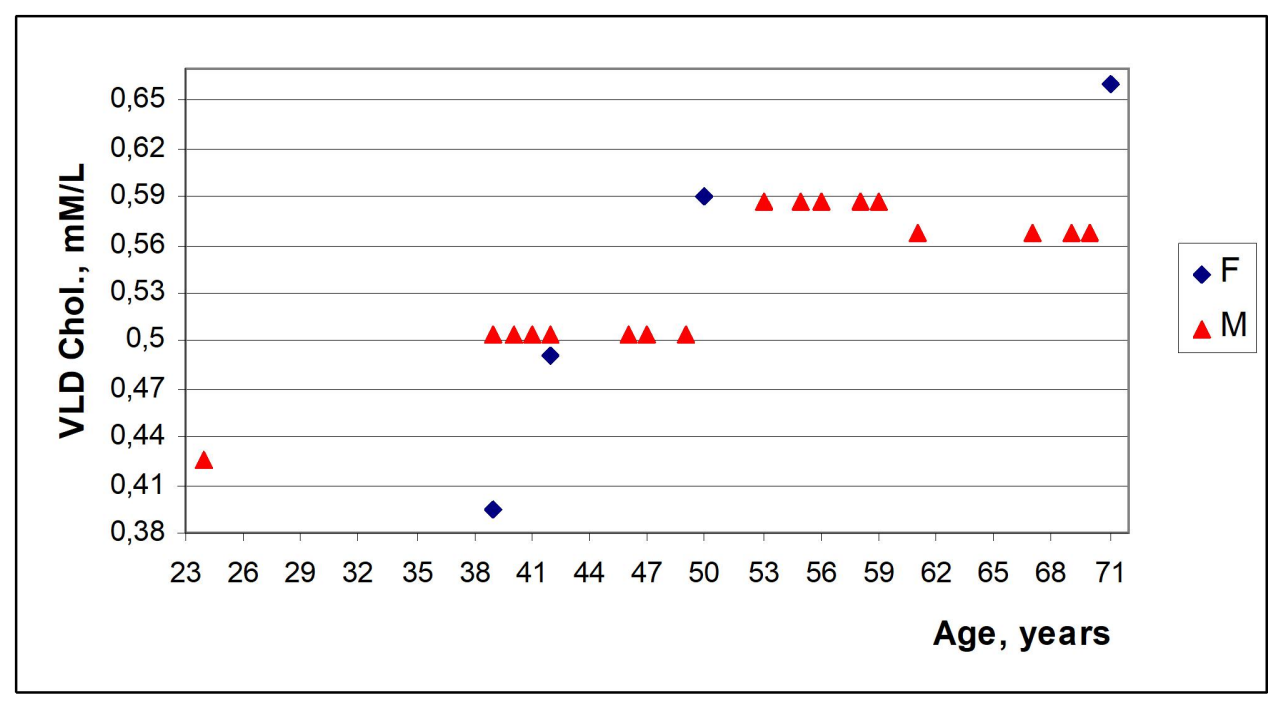

Fig. 5. Age and sex standards of very law-density lipoprotein plasma cholesterol

The analyzes were carried out according to the instructions described in the manual [5]. The analyzers "Pointe-180" ("Scientific", USA) and "Reflotron" (Boehringer Mannheim, BRD) were used with appropriate sets and a flamming spectrophotometer "СФ-47".

Norms are borrowed from the database of the Truskavetsian Scientific School of Balneology.

Results processed using the software package "Statistica 5.5".

\section{RESULTS AND DISCUSSION}

For the purpose of a one-scale evaluation of various parameters, all of them were recalculated in the Z-score by the formula:

$\mathrm{Z}=($ Variable/Norm -1)/Coefficient of Variation.

The endocrine profiles thus created (Fig. 6) can be divided into at least two networks. The first set includes parameters that are almost identical in stress-sensitive and stress-resistant individuals, namely: normal levels of triiodothyronine, mineralocorticoid and calcitonin activities, estimated by both daily urine and plasma parameters, and parathyroid activity, estimated by plasma levels .

The second set contains parameters that are more or less higher in stress-sensitive individuals than in stress-resistant individuals. First of all, these are moderately elevated levels of cortisol (actual) and testosterone (normalized by age and gender) in stress-sensitive versus upper-border in stress-resistant men $(+0,73 \pm 0,41 \mathrm{Z})$ and women $(+0,56 \pm 0,30 \mathrm{Z})$. Further, this is the $\mathrm{Ca} / \mathrm{K}$ plasma ratio, which reflects the sympathetic-vagal balance [4], as well as the parathyroid activity estimated by the parameters of daily urine. The discrepancy between the two estimates of parathyroid activity was previously detected in rats [6] and is interpreted respectively as situational (at the time of blood collection in the morning) and stationary (daily). By the way, this applies to other hormones, moreover, they are also defined in the hair and nails for the evaluation of permanent hormonal activity. 


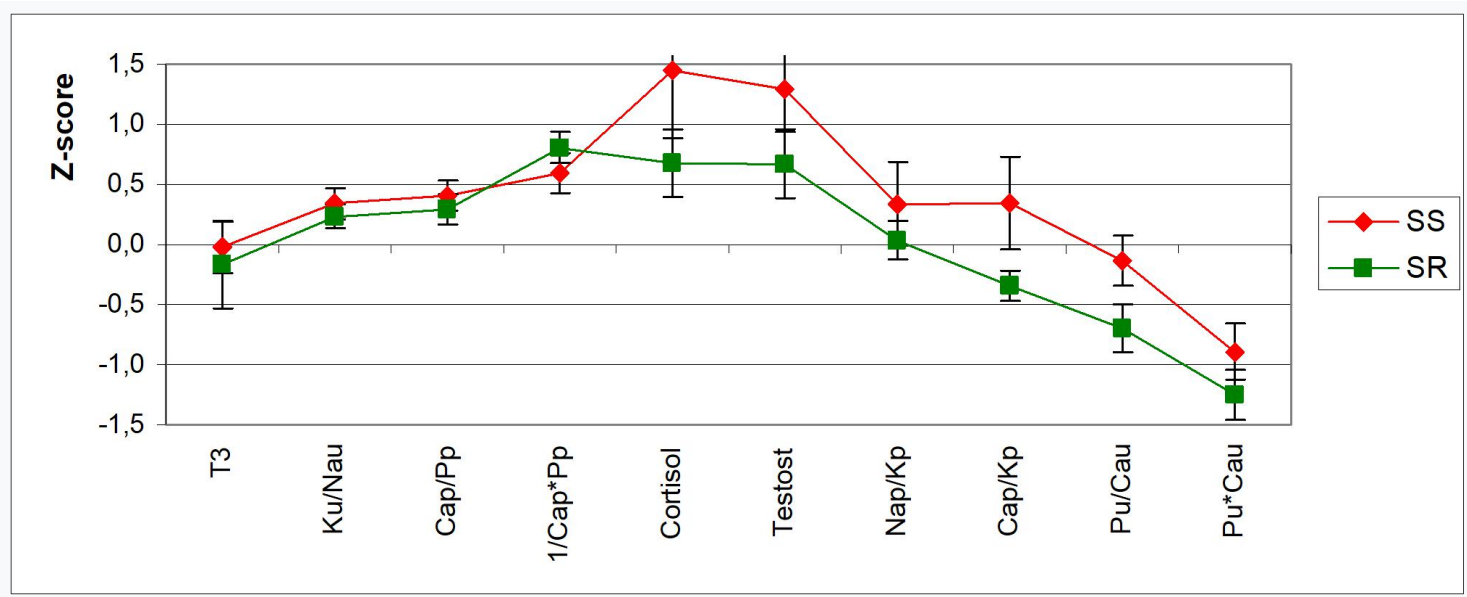

Fig. 6. Endocrine profiles of persons sensitive (SS) and resistant (SR) to stress

The analysis of Fig. 7 we think it is logical to start with the HRV parameters. As we can see, the entropy of HRV and SP VLF band is lower in stress-sensitive individuals than in stress-resistant individuals. The sensitivity of the immune status to stress is also accompanied by decreased excretion of creatinine, lower-bound natriuria, plasma sodium and potassium, normal plasma chloride levels, and increased its urinary excretion.

Instead, immune resistance to stress is characterized by lower-bound creatininuria, normal levels of natriuria, plasma sodium and potassium, upper-bound chloridemia, and elevated chloriduria.

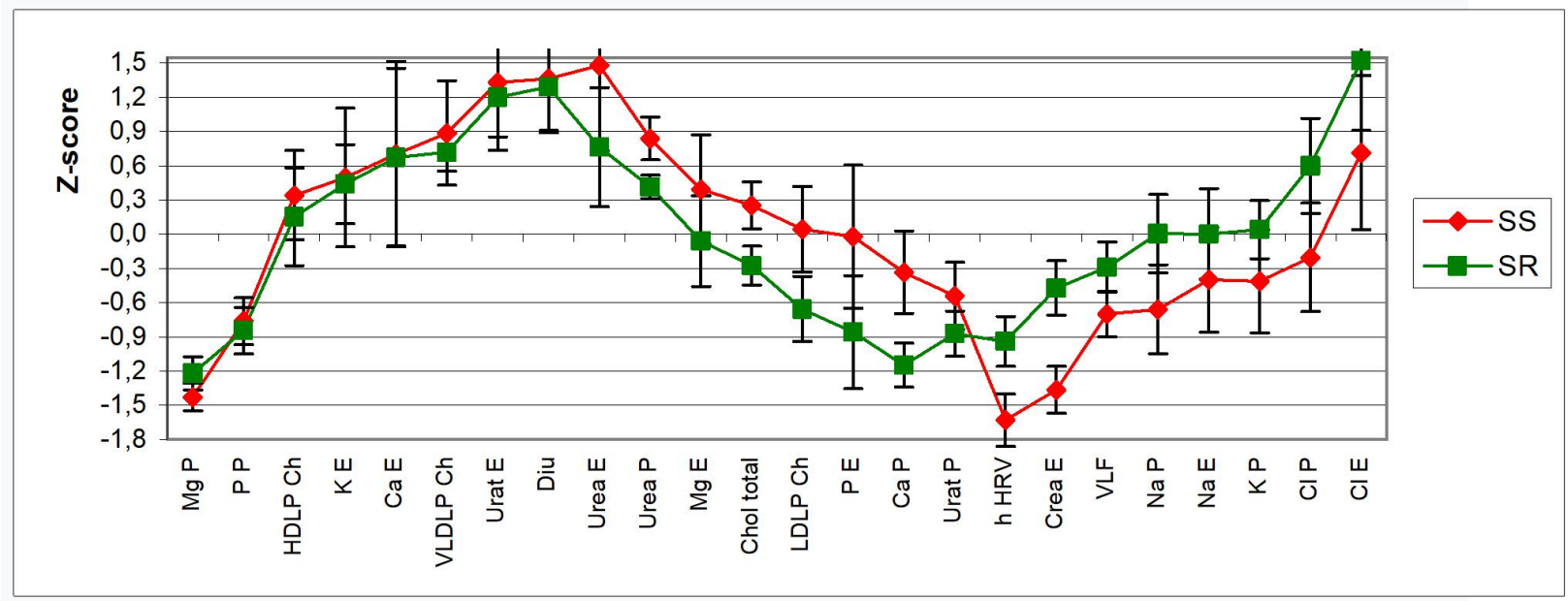

Fig. 7. HRV and Metabolic profiles of persons sensitive (SS) and resistant (SR) to stress

The inverse set is formed by metabolic parameters that are lower in stress-resistant individuals than in stress-sensitive individuals. In particular, in the first calciumemia and phosphaturia are lowered, LDLP Cholesterol level is lower boundary, total cholesterol in the lower area of normal, magnesiumuria is quite normal, plasma urea in the upper zone of normal, and urea excretion is upper boundary. Instead, stress-sensitive individuals have metabolic parameters listed in the lower, middle, or upper zones of the norm, upper limit, and elevated, respectively.

The last set is formed by parameters that are practically identical for the individuals of both clusters. In particular, elevated (daily diuresis and uricosuria), upper boundary (VLDLP 
Cholesterol and calciumuria), normal (potassium urine and plasma HDLP Cholesterol) and decreased (phosphatemia and magnesiumemia).

The method of discriminant analysis forward stepwise [12] revealed 8 variables that characterize the features of HRV as well as endocrine and metabolic profile of stress-sensitive and stress-resistant persons. Another 9 variables are not included in the model, but they are worth attention (Tables 1 and 2).

Table 1. Discriminant Function Analysis Summary for HRV, Endocrine and Metabolic Variables of stress-sensitive and stress-resistant individuals

Step 8, $N$ of vars in model: 8 ; Grouping: SS/SR; Wilks' $\Lambda$ : 0,438; approx. $\mathrm{F}_{(8,3)}=5,0 ; \mathrm{p}<0,0005$

\begin{tabular}{|c|c|c|c|c|c|c|c|c|c|}
\hline $\begin{array}{l}\text { Variables curre- } \\
\text { ntly in the model }\end{array}$ & $\begin{array}{l}\text { Reference } \\
\text { level (30) }\end{array}$ & $\mathrm{Cv}$ & $\begin{array}{l}\text { SS } \\
(20)\end{array}$ & $\begin{array}{l}\text { SR } \\
(20)\end{array}$ & $\begin{array}{l}\text { Wilks } \\
\Lambda\end{array}$ & $\begin{array}{l}\text { Parti- } \\
\text { al } \Lambda\end{array}$ & $\begin{array}{l}\text { F re- } \\
\text { move }\end{array}$ & $\begin{array}{l}\text { p-le- } \\
\text { vel }\end{array}$ & $\begin{array}{l}\text { Tole- } \\
\text { rancy }\end{array}$ \\
\hline Entropy HRV & $0,79 \pm 0,02$ & 0,127 & $0,62 \pm 0,02$ & $0,69 \pm 0,02$ &, 485 & ,903 & 3,3 & ,077 &, 742 \\
\hline VLF HRV, $\mathrm{msec}^{2}$ & $1411 \pm 148$ & 0,578 & $741 \pm 134$ & $1194 \pm 200$ & 467 &, 939 & 2,0 &, 165 & 663 \\
\hline Creatinin E mM/d & $11,0 \pm 0,52$ & 0,300 & $6,50 \pm 0,68$ & $9,44 \pm 0,79$ & 445 & ,985 &, 5 & ,498 & ,719 \\
\hline$(\mathrm{Pu} / \mathrm{Cau})^{0,5}$ & $2,40 \pm 0,11$ & 0,294 & $2,31 \pm 0,15$ & $1,90 \pm 0,14$ & 454 & 966 & 1,1 & 303 & 958 \\
\hline$(\mathrm{Cap} / \mathrm{Kp})^{0,5}$ & $0,71 \pm 0,01$ & 0,104 & $0,74 \pm 0,03$ & $0,69 \pm 0,01$ & 484 &, 905 & 3,2 &, 082 &, 702 \\
\hline Cholesterol, Z & 0 & & $0,25 \pm 0,21$ & $-0,28 \pm 0,17$ & 499 & 878 & 4,3 & ,046 &, 171 \\
\hline LDLP Cholest, Z & 0 & & $0,03 \pm 0,37$ & $-0,66 \pm 0,29$ & ,469 & ,934 & 2,2 & ,150 & ,181 \\
\hline Testosterone, $\mathrm{Z}$ & 0 & & $+1,30 \pm 0,36$ & $+0,67 \pm 0,28$ &, 524 &, 836 & 6,1 &, 020 & ,609 \\
\hline $\begin{array}{l}\text { Variables curre- } \\
\text { ntly not in model }\end{array}$ & $\begin{array}{l}\text { Reference } \\
\text { level (30) }\end{array}$ & $\mathrm{Cv}$ & $\begin{array}{l}\text { SS } \\
(20)\end{array}$ & $\begin{array}{l}\text { SR } \\
(20)\end{array}$ & $\begin{array}{l}\text { Wilks } \\
\Lambda\end{array}$ & $\begin{array}{l}\text { Parti- } \\
\text { al } \Lambda\end{array}$ & $\begin{array}{l}\mathrm{F} \text { to } \\
\text { enter }\end{array}$ & $\begin{array}{l}\text { p-le- } \\
\text { vel }\end{array}$ & $\begin{array}{l}\text { Tole- } \\
\text { rancy }\end{array}$ \\
\hline Sex Index & 1,5 & & $1,05 \pm 0,05$ & $1,35 \pm 0,11$ &, 433 & 989 & 34 & ,566 & 403 \\
\hline Urates Plasma, Z & 0 & & $-0,54 \pm 0,29$ & $-0,87 \pm 0,20$ & ,438 & ,999 &, 02 & ,899 & ,829 \\
\hline Urates $\mathrm{P}, \mu \mathrm{M} / \mathrm{L}$ & $366 \pm 8$ & 0,181 & $345 \pm 21$ & $291 \pm 18$ & ,438 & ,998 &, 05 & ,824 & ,651 \\
\hline Cholester, $\mathrm{mM} / \mathrm{L}$ & $5,48 \pm 0,08$ & 0,184 & $5,77 \pm 0,22$ & $5,15 \pm 0,15$ & ,434 & ,990 &, 31 & ,582 &, 156 \\
\hline LDLP Ch, mM/L & $3,61 \pm 0,08$ & 0,179 & $3,68 \pm 0,25$ & $3,12 \pm 0,17$ & ,437 & ,997 & ,08 & ,785 & ,095 \\
\hline Calcium P, mM/L & $2,30 \pm 0,02$ & 0,065 & $2,25 \pm 0,05$ & $2,13 \pm 0,03$ & ,437 & ,998 &, 07 &, 795 & ,551 \\
\hline Urea Plas, $\mathrm{mM} / \mathrm{L}$ & $5,00 \pm 0,26$ & 0,330 & $6,39 \pm 0,31$ & $5,68 \pm 0,17$ &, 432 & ,987 & 40 &, 532 & 863 \\
\hline Urea Excr., mM/d & $458 \pm 13$ & 0,186 & $584 \pm 64$ & $523 \pm 44$ &, 437 & ,996 &, 11 & ,743 & ,347 \\
\hline Cortisol P, nM/L & $405 \pm 20$ & 0,315 & $590 \pm 72$ & $492 \pm 36$ & ,425 & ,969 & ,95 & ,337 & ,364 \\
\hline
\end{tabular}

Table 2. Summary of Stepwise Analysis for HRV, Endocrine and Metabolic Variables ranked by criterion $\Lambda$

\begin{tabular}{|l|l|l|l|l|l|}
\hline Variables currently in the model & $\begin{array}{l}\text { F to } \\
\text { enter }\end{array}$ & $\begin{array}{l}\text { p- } \\
\text { level }\end{array}$ & $\boldsymbol{\Lambda}$ & $\begin{array}{l}\text { F- } \\
\text { value }\end{array}$ & $\begin{array}{l}\text { p- } \\
\text { level }\end{array}$ \\
\hline Testosterone normalized, Z & 10,6 &, 002 &, 782 & 10,6 &, 002 \\
\hline Entropy HRV & 9,9 &, 003 &, 617 & 11,5 &, 0001 \\
\hline Creatinine Excretion, mM/24h & 4,0 &, 053 &, 555 & 9,6 & $10^{-4}$ \\
\hline$(\mathrm{Pu} / \mathrm{Cau})^{0,5}$ as Parathyroid Activity & 1,7 &, 198 &, 529 & 7,8 &, 0001 \\
\hline$(\mathrm{Cap} / \mathrm{Kp})^{0,5}$ & 1,0 &, 323 &, 514 & 6,4 &, 0003 \\
\hline Cholesterol total normalized, Z $^{-5}$ & 1,2 &, 288 &, 496 & 5,6 &, 0004 \\
\hline LD LP Cholesterol normalized, Z & 2,0 &, 168 &, 467 & 5,2 &, 0005 \\
\hline VLF HRV, msec $^{2}$ & 2,0 &, 165 &, 438 & 5,0 &, 0005 \\
\hline
\end{tabular}

Information about the variables included in the model is condensed in the canonical discriminant root. The sum of products of raw coefficients on the value of discriminant variables together with the constant (Table 3) gives the values of root for each person and allow their visualization. 
Table 3. Standardized, Structural and Raw Coefficients and Constant for Canonical Variables and their Z-scores for individuals whose immunity is susceptible or resistant to stress

\begin{tabular}{|c|c|c|c|c|c|}
\hline $\begin{array}{l}\text { Variables currently } \\
\text { in the model }\end{array}$ & $\begin{array}{l}\text { Stress- } \\
\text { sensitive }\end{array}$ & $\begin{array}{l}\text { Stress- } \\
\text { resistant }\end{array}$ & $\begin{array}{l}\text { Standar- } \\
\text { dized }\end{array}$ & Structural & Raw \\
\hline Testosterone & $+1,30 \pm 0,36$ & $+0,67 \pm 0,28$ & ,691 & ,466 & ,078 \\
\hline$(\mathrm{Pu} / \mathrm{Cau})^{0,5}$ as PTA & $-0,13 \pm 0,21$ & $-0,70 \pm 0,20$ &, 252 & 286 & ,394 \\
\hline Cholesterol total & $+0,25 \pm 0,21$ & $-0,28 \pm 0,17$ & 1,126 & 284 & 1,331 \\
\hline$(\mathrm{Cap} / \mathrm{Kp})^{0,5}$ & $+0,34 \pm 0,39$ & $-0,34 \pm 0,13$ &, 490 & 242 & 5,150 \\
\hline LD LP Cholesterol & $+0,03 \pm 0,37$ & $-0,66 \pm 0,29$ &,- 803 & 213 &,- 538 \\
\hline Creatinine Excretion & $-1,36 \pm 0,20$ & $-0,47 \pm 0,24$ &,- 192 &,- 405 &,- 058 \\
\hline Entropy HRV & $-1,63 \pm 0,23$ & $-0,94 \pm 0,22$ &,- 483 &,- 317 & $-4,848$ \\
\hline VLF HRV & $-0,70 \pm 0,20$ & $-0,29 \pm 0,22$ &,- 406 &,- 264 &,- 00054 \\
\hline & \multicolumn{2}{|c|}{ Eigenvalue $=1,282$} & & Constant & $-1,695$ \\
\hline
\end{tabular}

As we can see (Fig. 8), in individuals whose immunity is sensitive to stress, the discriminant root is usually higher than that of resistant individuals. This reflects, first and foremost, significantly higher than the sex and age standards, the testosterone level in the former, while in the latter it is in the upper normal range. Therefore, testosterone sensitizes the immune system to stress suppression.

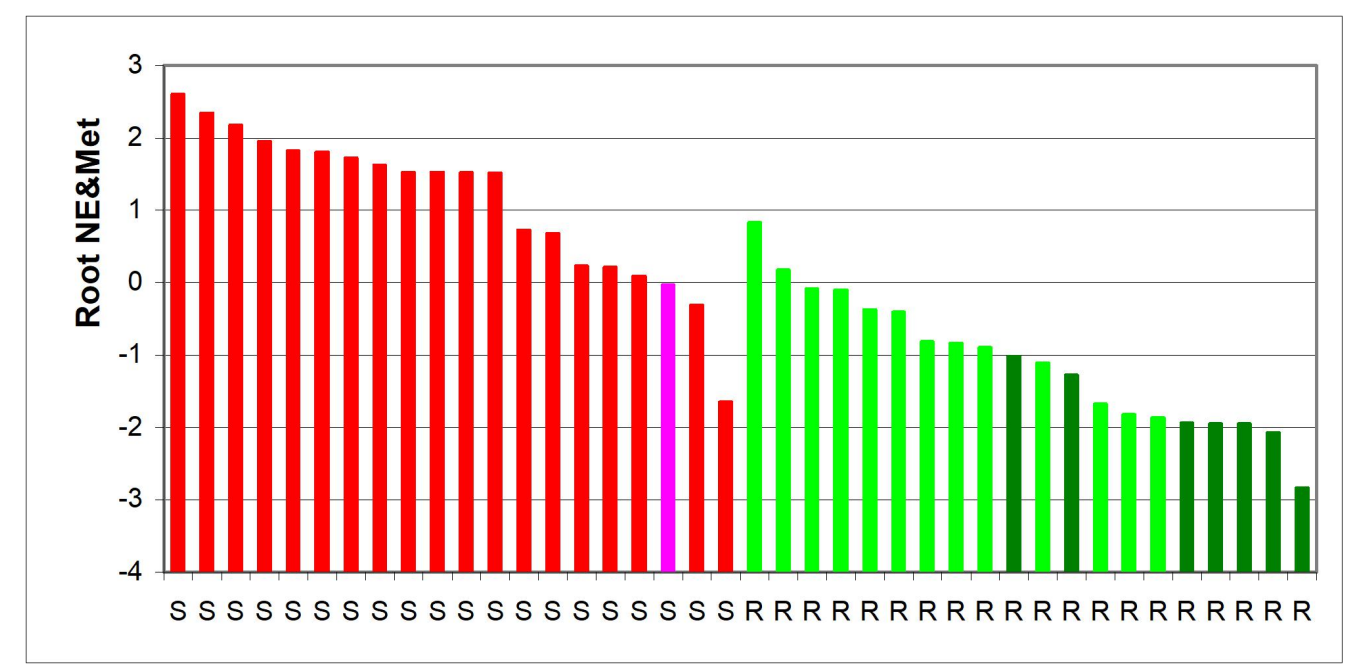

Fig. 8. Individual values of the HRV-Endocrine-Metabolic discriminant root of persons whose immunity is susceptible $(S)$ or resistant $(R)$ to stress

Less influential sensitizing (immunosuppressive) factors are, apparently, total cholesterol and $\mathrm{Ca} / \mathrm{K}$-ratio of plasma, levels of which in stress-sensitive individuals are in the upper zone of normal, while in stress-resistant in the lower zone.

On the other hand, the significantly reduced spectral power of the VLF band HRV (as well as the entropy of the HRV, apparently due to its major VLF component) gives grounds to consider it a desensitizing (immunoprotective) factor.

It is speculated that VLF band HRV $(0,04 \div 0,015 \mathrm{~Hz})$ associated with oscillation blood levels of renin $(0,04 \mathrm{~Hz})$ and epinephrine $(0,025 \mathrm{~Hz})$, reflects thermoregulatory cycles, cerebral ergotropic and metabolotropic outflows, activation of cerebral sympathetic-adrenal system [1,3,7,14], sympathetic activity [13]. Resently, we showed [2] that the absolute spectral power of the VLF band correlate significantly with the markers of the vagus tone directly, and with the markers of sympathetic tone inversely. This gives us reason to believe 
that VLF band is vagus marker. This is consistent with the interpretation of the increase in plasma $\mathrm{Ca} / \mathrm{K}$-ratio as a reflection of sympathotonic shift of sympathetic-vagal balance.

Another desensitizing (immunoprotective) factor, following this algorithm, can be considered creatinineuria, the level of which is significantly reduced in stress-sensitive individuals, whereas in stress-resistant persons it is only in the lower zone of normal. The latter, however, revealed lower boundary levels of parathyroid activity and LD LP Cholesterol, whereas in stress-sensitive individuals they are quite normal. Therefore, these two factors can also be considered desensitizing (immunoprotective).

In the analysis of gender differences, it is revealed that the discriminant roots are lower in women than in men, but this is the case in each cluster (Fig. 9). Therefore, it is only fair that gender was not included in the discriminatory model, that is, it is not a factor that determines the nature of the effect of stress-induced sympathotonic shift of autonomic regulation on immune status.

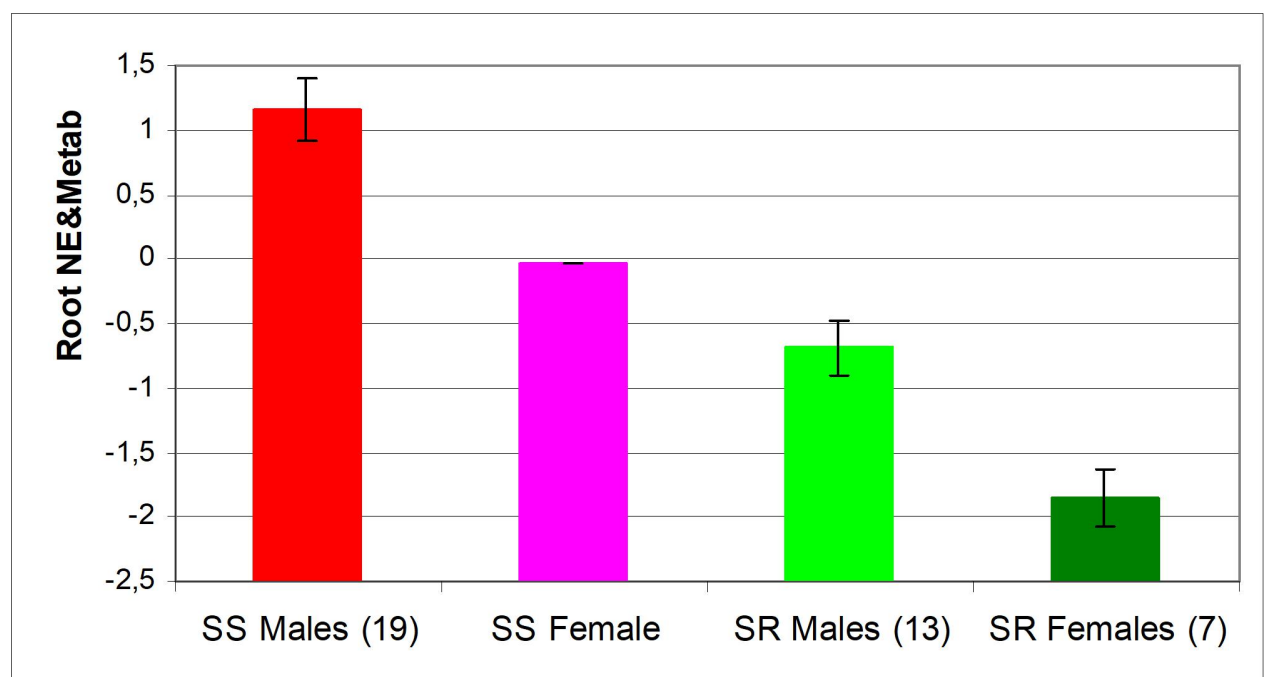

Fig. 9. Average values (Means \pm SE) of the HRV-Endocrine-Metabolic discriminant root of males and females whose immunity is sensitive (S) or resistant $(\mathrm{R})$ to stress

The accuracy of retrospective classification of persons whose immune status is sensitive to stress is $85 \%$ (three errors), and stress-resistant persons $90 \%$ (two errors), ie an overall accuracy of $87,5 \%$.

A detailed analysis of the mechanisms of sensitization and desensitization of neural, endocrine and metabolic factors will be the topic of the next article. And as a conclusion, let us limit ourselves to the announcement of integral profiles (Fig. 10). 


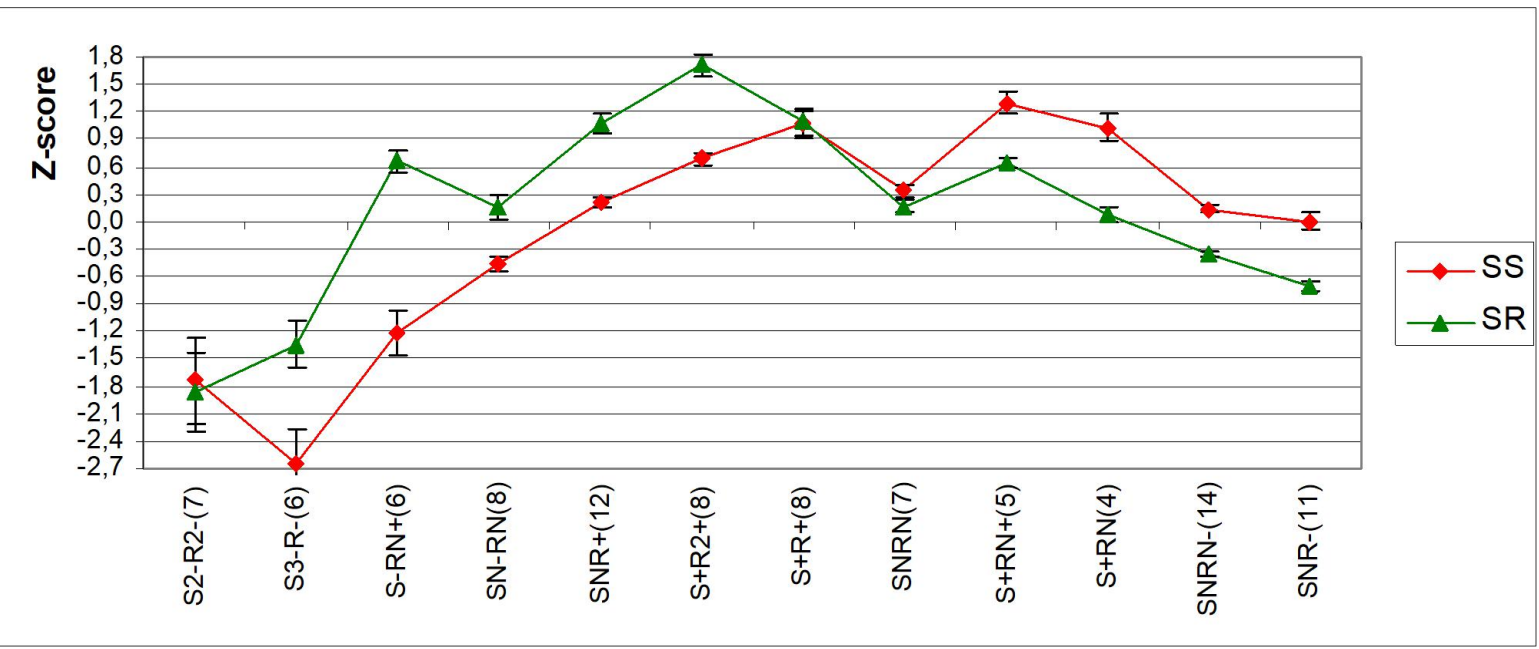

Fig. 10. Average values (Means \pm SE) of the deviations in parameters constellations (n) of patients whose immunity is sensitive $(S)$ or resistant $(R)$ to chronic stress

\section{ACKNOWLEDGMENT}

We express sincere gratitude to administration of JSC "Truskavets'kurort" and "Truskavets' SPA" as well as clinical sanatorium "Moldova" for help in conducting this investigation.

\section{ACCORDANCE TO ETHICS STANDARDS}

Tests in patients are conducted in accordance with positions of Helsinki Declaration 1975, revised and complemented in 2002, and directive of National Committee on ethics of scientific researches. During realization of tests from all participants the informed consent is got and used all measures for providing of anonymity of participants. For all authors any conflict of interests is absent.

\section{REFERENCES}

1. Baevskiy RM, Ivanov GG. Heart Rate Variability: theoretical aspects and possibilities of clinical application [in Russian]. Ultrazvukovaya i funktsionalnaya diagnostika. 2001; 3: 106-127.

2. Barylyak LG, Tsymbryla VV, Zukow W, Popovych IL. Relationships between parameters of plasma lipoproteines profile and heart rate variability. Journal of Education, Health and Sport. 2019; 9(12): 238-253.

3. Berntson GG, Bigger JT jr, Eckberg DL, Grossman P, Kaufman PG, Malik M, Nagaraja HN, Porges SW, Saul JP, Stone PH, Van der Molen MW. Heart Rate Variability: Origines, methods, and interpretive caveats. Psychophysiology. 1997; 34: 623-648.

4. Fajda OI, Drach OV, Barylyak LG, Zukow W. Relationships between $\mathrm{Ca} / \mathrm{K}$ plasma ratio and parameters of Heart Rate Variability at patients with diathesis urica. Journal of Education, Health and Sport. 2016; 6(1): 295-301.

5. Goryachkovskiy AM. Clinical Biochemistry [in Russian]. Odesa: Astroprint; 1998: 608 p.

6. Gozhenko AI, Zukow W, Polovynko IS, Zajats LM, Yanchij RI, Portnichenko VI, Popovych IL. Individual Immune Responses to Chronic Stress and their Neuro-Endocrine Accompaniment. RSW. UMK. Radom. Torun; 2019: 200 p.

7. Heart Rate Variability. Standards of Measurement, Physiological Interpretation, and Clinical Use. Task Force of ESC and NASPE. Circulation. 1996; 93(5): 1043-1065.

8. Hiller G. Test for the quantitative determination of HDL cholesterol in EDTA plasma with Reflotron ${ }^{\circledR}$. Klin Chem. 1987; 33: 895-898. 
9. Hrytsak YaL, Barylyak LG, Zukow W, Popovych IL. Cluster analysis of hormonal constellation at women and men with harmonious and disharmonious general adaptation reactions. Journal of Education, Health and Sport. 2016; 6(4): 141-150.

10. Ivassivka SV, Popovych IL, Aksentiychuk BI, Flyunt IS. Physiological Activity of Uric Acid and its Role in the Mechanism of Action of Naftussya Water [in Ukrainian]. Kyiv. Computerpress; 2004: 163 p.

11. Khmelevskyi YV, Usatenko OK. Basic Biochemical Constants of Humans at Norm and at Pathology [in Russian]. Kyiv. Zdorovya; 1987: 160 p.

12. Klecka WR. Discriminant Analysis [trans. from English to Russian] (Seventh Printing, 1986). In: Factor, Discriminant and Cluster Analysis. Moskva: Finansy i Statistika; 1989: 78-138.

13. Korkushko OV, Pysaruk AV, Shatylo VB. The value of heart rate variability analysis in cardiology: age aspects [in Russian]. Circulation and Hemostase. 2009; 1-2: 127-139.

14. Kotelnikov SA, Nozdrachov AD, Odinak MM, Shustov EB, Kovalenko IYu, Davidenko VYu. Heart rate variability: understanding of the mechanisms [in Russian]. Fiziologiya cheloveka. 2002; 28(1): 130-143.

15. Lukyanchenko OI, Gozhenko OA, Mel'nyk OI, Zukow W, Popovych IL. Features of the immune profile and microbiota in persons whose immune status is susceptible or resistant to chronic stress. Journal of Education, Health and Sport. 2019; 9(3): 601-611.

16. Mel'nyk OI, Lukyanchenko OI, Gozhenko OA, Popovych IL. Features of the parameters of EEG in persons whose immune status is susceptible or resistant to chronic stress. Experimental and Clinical Physiology and Biochemistry. 2019; 2(86): 11-23.

17. Popadynets' OO, Gozhenko AI, Zukow W, Popovych IL. Relationships between the entropies of EEG, HRV, immunocytogram and leukocytogram. Journal of Education, Health and Sport. 2019; 9(5): 651-666. 